\title{
Synthesis, Growth and Characterization of 4-Benzeneazoaniline Single Crystal
}

\author{
T. Kishore Kumar ${ }^{1}$, S. Janarthanan ${ }^{1}$, S. Pandi ${ }^{1}$, M. Victor Antony Raj ${ }^{2}$, J. \\ Kanagalakshmi ${ }^{3}$, D. Prem Anand ${ }^{3 *}$ \\ ${ }^{1}$ Department of Physics, Presidency College, Chennai - 600005, India \\ ${ }^{2}$ Department of Physics, Loyola College, Chennai - 600034, India \\ ${ }^{3}$ Department of Physics, St. Xavier's College, Palayamkottai - 627002, India \\ *Corresponding Author: dpremanand@yahoo.co.in
}

\begin{abstract}
A new organic nonlinear optical material 4-Benzeneazoaniline $\left(C_{12} H_{11} N_{3}\right)$ was synthesized by diazotization and diazocoupling mechanisms. Single crystal of 4-Benzeneazoaniline was grown by slow evaporation of methanol solution at room temperature. Transparent crystals with size up_to $13 \times 4 \times 4 \mathrm{~mm}^{3}$ were obtained. Single crystal X-ray diffractometer was utilized to measure the unit cell parameters and to confirm the crystal structure. The structure of compound was further confirmed by FTIR, ${ }^{1} \mathrm{H} \mathrm{\&}{ }^{13} \mathrm{C} N M R$ and mass spectral analyses. The UV-Vis-NIR result shows that the crystal has a sharp cut off at $220 \mathrm{~nm}$ and is nearly $75 \%$ transparent over a wide wavelength range enabling it for application in the UV region. The optical energy gap of 4Benzeneazoaniline was found to be $3.4 \mathrm{eV}$. Thermal properties of crystals were investigated using thermogravimetric and differential scanning calorimetric analyses, which indicated that the material does not decompose before melting. The NLO test confirms the second harmonic signal generation in the sample.
\end{abstract}

Keywords: crystal growth, X-ray diffraction, $N M R, D S C$

\section{INTRODUCTION}

Second order nonlinear optical materials have recently attracted much attention because of their potential applications in emerging technologies [1-2]. According to the roadmaps of optoelectronics industry, the growing demand in the field of data communication requires that optical fibre network operate at the rate of tetra byte per second by the year 2010. A world wide effect is underway to achieve that goal so as to enable high speed optical technology, optical communication, optical computing, optical information processing, optical disc data storage, laser fusion reaction, laser remote sensing, color display, and medical diagnostics. Moreover organic crystals have received a great deal of interest in recent years due to their extremely large 
optical linearity as compared with most of the inorganic crystals that are transparent in the visible region [3-4]. An essential condition to realize these properties in a crystal is required, if appreciable effects are to be achieved in molecular materials [5-6].

In view of the above requirements, it is mandatory to search for few organic NLO crystals, which possess shorter cutoff wavelength, optical quality, sufficiently large nonlinear coefficient, transparency in the UV region and high damage threshold. 4-Benzeneazoaniline (4BAA), commonly known as p-aminoazobenzene is a nonlinear optical crystal with molecular formula $\mathrm{C}_{12} \mathrm{H}_{11} \mathrm{~N}_{3}$. It is a well known material in dyeing industry [7]. It crystallizes in noncentro symmetric space group $P 2{ }_{1}$. Recently, the studies on the dependence of the second order susceptibilities for the two principle second order tensor components in DC and UV-laser fields of 4BAA were investigated by Krishnakumar et al [8]. Additionally surface enhanced Raman scattering spectra and cyclic voltametry studies were used to detect the products of oxidation and reduction in 4BAA. The results indicated that the oligomerization products are formed during the oxidation of 4BAA on gold electrode [9]. Apart from these observations the kinetic properties of 4BAA degradation under nitrifying condition and the spectral properties of encapsulated 4BAA dyes were reported [10]. However, to our best knowledge no systematic studies of 4BAA have been made. In continuation of our work on nonlinear optical materials [11-13], an attempt has been made to synthesize, grow and characterize 4BAA single crystal from 1,2-diamino5benzoazobenzene.

\section{SYNTHESIS}

The preparation of 4BAA is effected essentially in two steps. In the first step diazotization of aniline with nitrite takes place in a hydrochloric acid medium with formation of diphenyl triazine as diazoamino compound. By an acid catalyzed reaction this compound is subsequently isomerized to 4BAA. The starting materials aniline, concentrated hydrochloric acid, sodium nitrite, sodium acetate, aniline hydrochloride, and glacial acetic acid are commercially available. The first step is the preparation of 1,2-diamino5-benzoazobenzene (DBAB). $75 \mathrm{~mL}$ of water, 20 $m L$ of concentrated hydrochloric acid and $13.7 \mathrm{~mL}$ of aniline are taken in a $500 \mathrm{~mL}$ beaker. The reagents are vigorously stirred using a mechanical stirrer. $50 \mathrm{~g}$ of crushed ice was added to the reagents. To this mixture a solution of $5.2 \mathrm{~g}$ of sodium nitrite in $12 \mathrm{~mL}$ of water were poured. Then a solution of $21 \mathrm{~g}$ of sodium acetate dissolved in $40 \mathrm{~mL}$ of water was added to the mixture. A yellow precipitate of DBAB begins to form immediately. Finally the precipitate was washed with cold triple distilled water. The yielded DBAB was spread on a sheet of filter paper and dried. Approximately $9 \mathrm{~g}$ of DBAB were obtained. Nearly $5 \mathrm{~g}$ of DBAB was dissolved in $15 \mathrm{~g}$ of aniline with $2.5 \mathrm{~g}$ of aniline hydrochloride. The beaker containing the reagents were placed in a hot water bath maintained at a temperature of $40-45^{\circ} \mathrm{C}$. The reaction mixture was allowed to stand for 30 minutes. Then $15 \mathrm{~mL}$ of glacial acetic acid diluted with an equal volume of water was added into the reaction mixture. The mixture was allowed to stand for 5 minutes and washed with $500 \mathrm{~mL}_{\text {of }} \mathrm{CCl}_{4}$ so as to remove any traces of excess aniline in the form of its soluble acetate. The mixture was allowed to stand for thirty minutes. Nearly $3 \mathrm{~g}$ of 4BAA was obtained. This crude 4BAA was once again washed with $20 \mathrm{~mL}$ of $\mathrm{CCl}_{4}$ to obtain pure 4BAA. The reaction scheme is shown in Figure 1. 

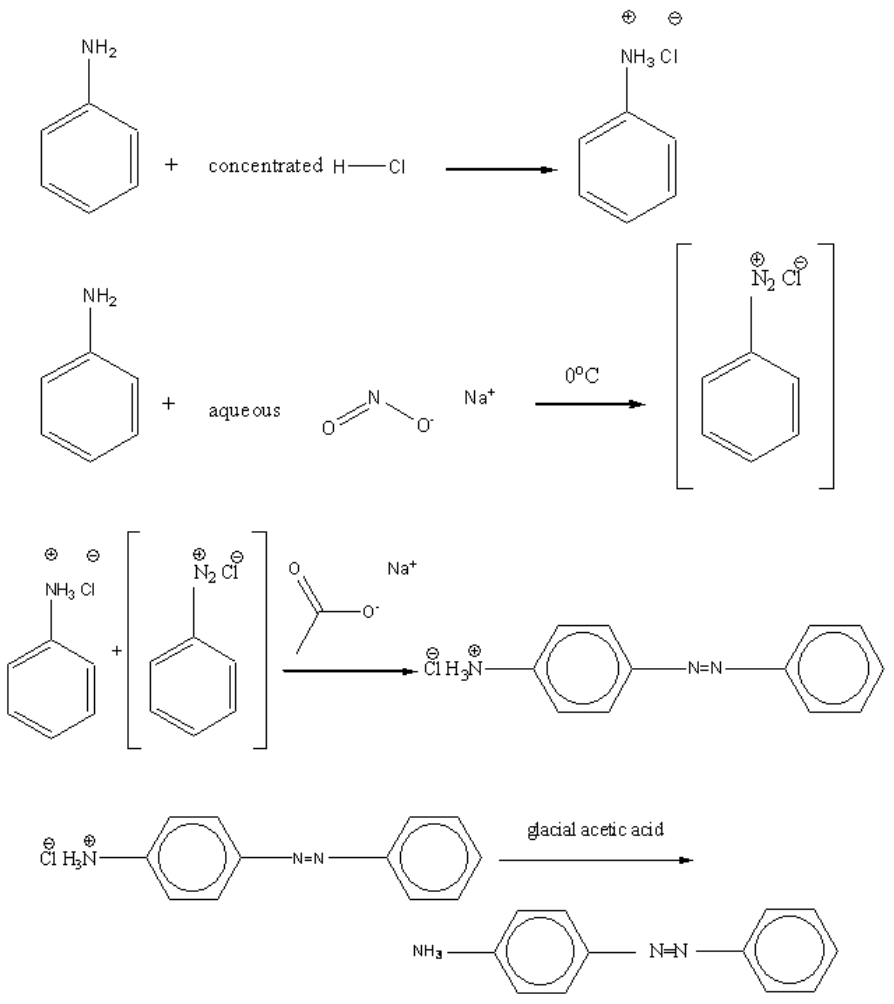

Figure 1. Reaction schemes of 4BAA

\section{SOLUBILITY AND CRYSTAL GROWTH}

To select a suitable solvent, the solubility of 4BAA in different solvents such as water, methanol and ethanol were determined. The 4BAA solution was prepared in methanol solution and maintained at $30^{\circ} \mathrm{C}$ with continuous stirring in order to ensure homogeneous temperature and concentration over the entire volume of the solution. On reaching saturation, the content of the solution was analyzed gravimetrically and this process was repeated for every $5^{\circ} \mathrm{C}$ in the temperature range $30-50^{\circ} \mathrm{C}$. The solubility curve for 4BAA is shown in Figure 2. Methanol was found to be the best solvent to grow 4BAA crystals. To grow the single crystal, saturated solution of 4BAA was prepared in methanol at room temperature $\left(30^{\circ} \mathrm{C}\right)$. The saturated solution was filtered twice to remove the suspended impurities and kept at $30^{\circ} \mathrm{C}$ in a constant temperature bath with an accuracy $\pm 0.01{ }^{\circ} \mathrm{C}$. After two days, orange color bar shaped crystals were obtained. Twin free crystals of considerable size bar shaped crystal having reasonable transparency were obtained. As grown single crystals of 4BAA is shown in Figure 3. 




Figure 2. Solubility curve of 4BAA as a function of temperature

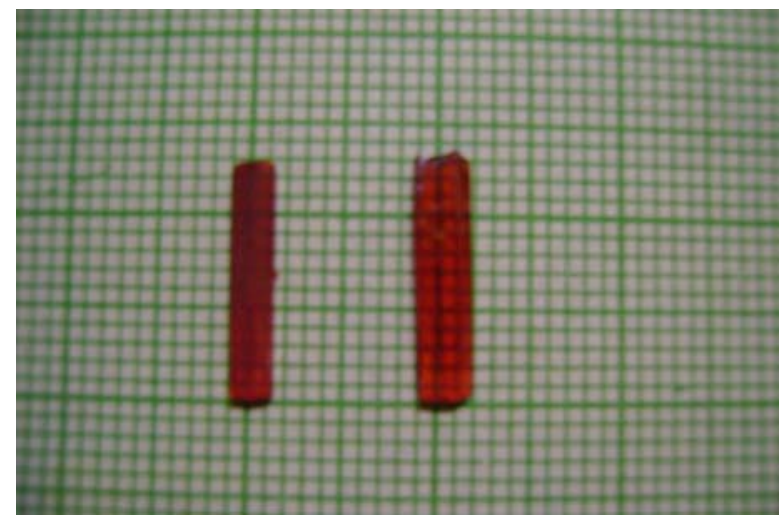

Figure 3. Photograph of as grown 4BAA single crystal

\section{SINGLE CRYSTAL XRD}

Single crystal XRD data of the grown 4BAA crystals were obtained using a single crystal X-ray diffractometer (model: Bruker-Nonius Kappa Apex II CCD). The 4BAA crystal retained its monoclinic structure with lattice parameters $a=13.64 \hat{A}, b=5.58 \AA, c=13.54 \AA$ and $\alpha=90^{\circ}$, $\beta=98.49^{\circ}, \gamma=90^{\circ}$ and $V=1038.16 \mathrm{~A}^{3}$ with noncentrosymmetric space group $P 2{ }_{1}$. The unit cell parameters derived are in very good agreement with the corresponding reported values [8].

\section{FTIR}

FTIR analysis of 4BAA was carried out to investigate the presence of functional groups. FTIR spectrum was recorded in the range of 450-4000 $\mathrm{cm}^{-1}$ employing Bruker model IFS 66V FTIR spectrometer. Figure 4 shows the FTIR spectrum of 4BAA. The strong peaks appearing in the region between 1305 and $1229 \mathrm{~cm}^{-1}$ are attributed to aromatic C-N stretching. Unsymmetrical 
Para substituted azobenzenes are identified at $1445 \mathrm{~cm}^{-1}$. A peak at $1596 \mathrm{~cm}^{-1}$ corresponds to N$\mathrm{H}$ bending mode. The aromatic $\mathrm{C}-\mathrm{H}$ stretching is positioned at $3027 \mathrm{~cm}^{-1}$. The sharp peaks at 3350 and $3380 \mathrm{~cm}^{-1}$ corresponds to the associated $\mathrm{N}-\mathrm{H}$ bands.

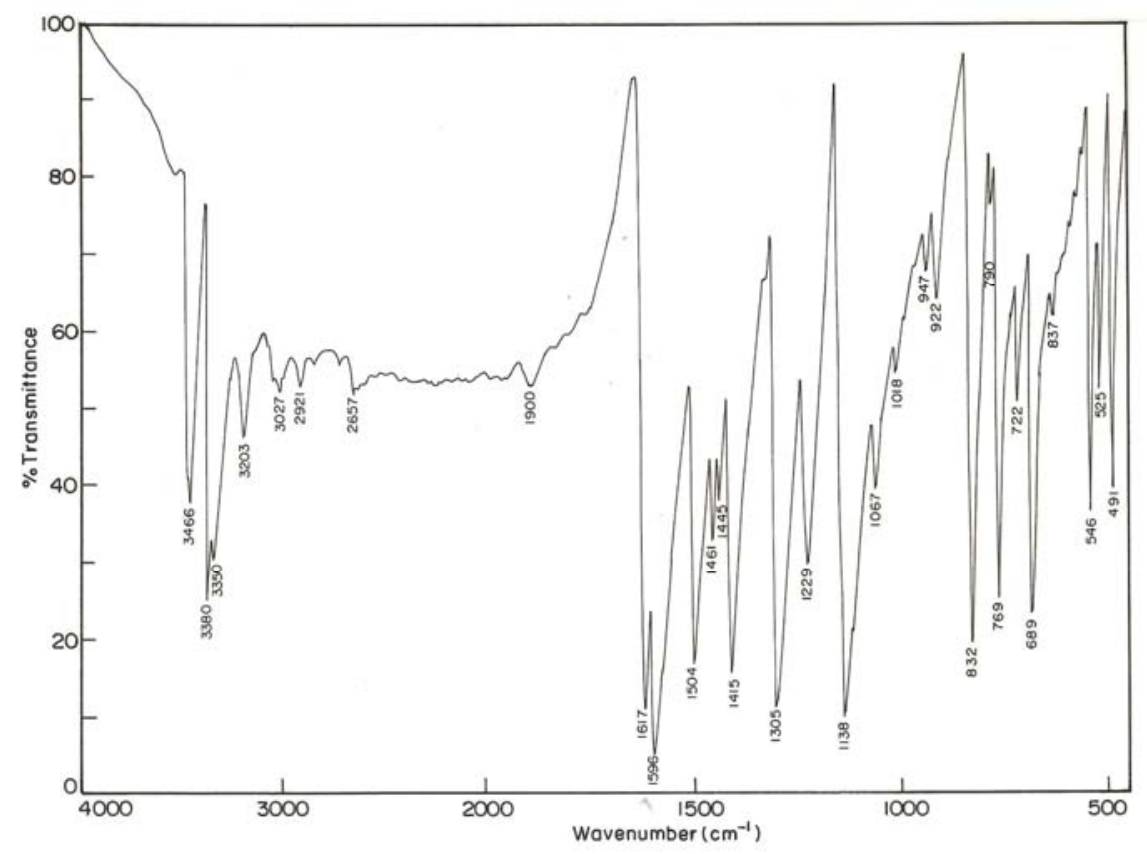

Figure 4. FTIR spectrum of 4BAA

\section{UV-Vis-NIR STUDIES}

The UV-Visible study of the grown crystal was carried out by VARIAN CARRY 5E spectrometer. The absorption spectrum (Figure 5) shows the grown crystal has lower cutoff wavelength around $220 \mathrm{~nm}$. Near UV region, absorption arises from electronic transition associated within the 4BAA moiety. The orbital $\pi$ electron delocalization in the molecule may be due to the mesomeric effect. This $\pi$ electron dislocation is responsible for its nonlinear optical response and absorption in near UV region [14]. From the UV-Visible data we have plotted a graph of absorbance verses photon energy in $\mathrm{eV}$ and from the graph it can be said that band gap is direct type [15]. Thus the grown crystal has a good transmission in UV as well as in visible region. The wide range of transparency of the grown crystal is an added advantage in the field of optoelectronics applications [16]. 


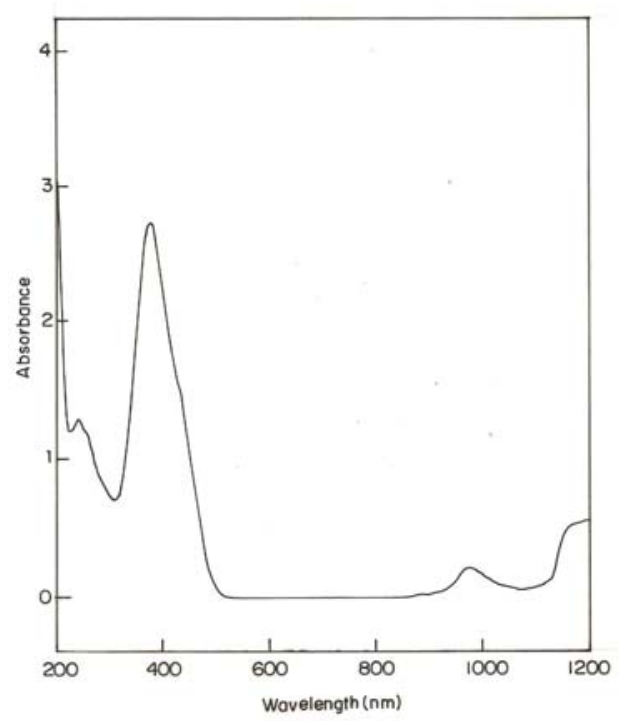

Figure 5. UV-Vis-NIR spectrum of 4BAA

\section{7. ${ }^{1} \mathrm{H}$ AND ${ }^{13} \mathrm{C}$ NMR SPECTRAL STUDIES}

In order to analyze carbon-hydrogen bonded network, ${ }^{1} \mathrm{H}$ and ${ }^{13} \mathrm{C}$ NMR spectra were recorded using a Bruker ARX 300 spectrometer in $\mathrm{CDCl}_{3}$ at $300 \mathrm{~K}$. The structure of 4BAA is shown in Figure 6. ${ }^{1} \mathrm{H}$ and ${ }^{13} \mathrm{C}$ spectra are shown in Figures 7 and 8 respectively. In ${ }^{1} \mathrm{H}$ spectrum, a two proton sharp doublet at $6.63 \mathrm{ppm}$ obtained corresponds to the protons present in the ortho to the free amino group attached to carbon in the benzene ring. A single proton present para to the azo group in another benzene ring shows a sharp doublet at $7.34 \mathrm{ppm}$. A two proton sharp triplet observed at $7.47 \mathrm{ppm}$ corresponds to the protons situated at the meta to the azo group in the another benzene ring. The remaining four aromatic protons present ortho to the azo groups in the both benzene rings appears as a multiplet between 7.78 to $7.86 \mathrm{ppm}$. A broad peak at $3.98 \mathrm{ppm}$ corresponds to the free amine group present in the compound. From the ${ }^{13} \mathrm{C}$ NMR spectrum the presence of different types of carbons in the compound can be understood. As expected the ${ }^{13} \mathrm{C}$ NMR spectra shows eight peaks as follows 114.2, 117.4, 122.4, 149.8, 153.0, 125.1, 129.9 and $145.5 \mathrm{ppm}$. These peaks are attributed to eight different carbons present in the compound.



Figure 6. The structure of 4BAA 


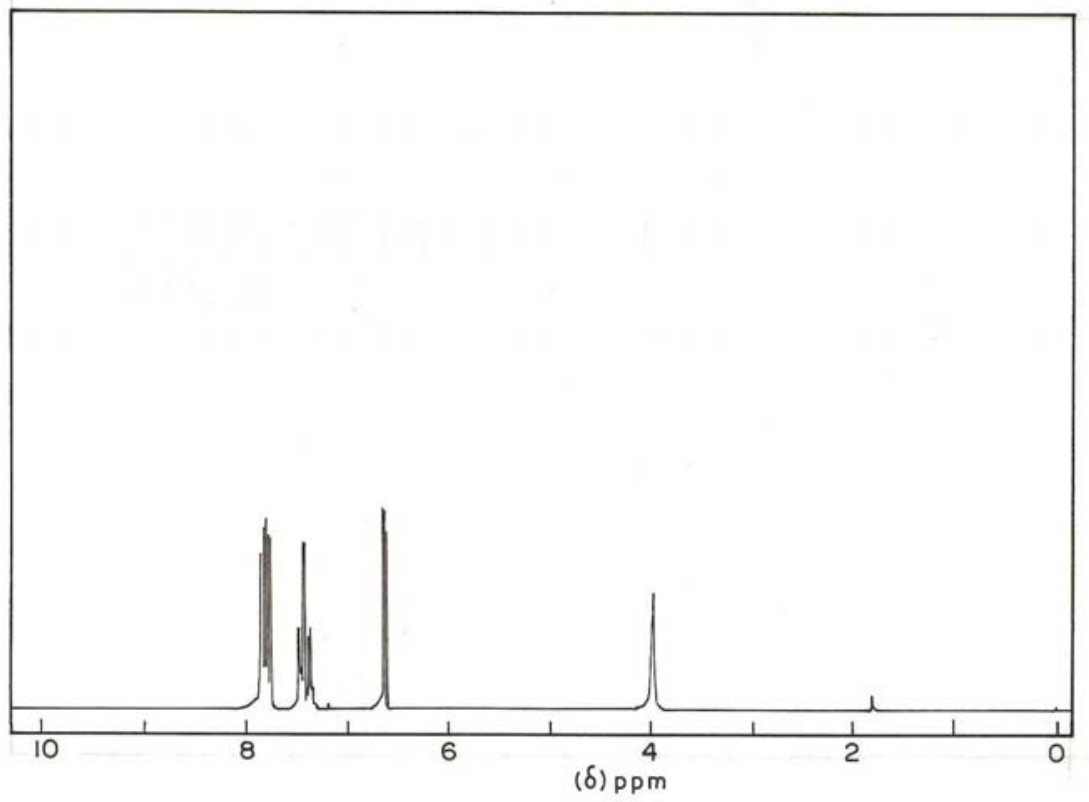

Figure 7. ${ }^{1} \mathrm{H}$ NMR spectrum of $4 \mathrm{BAA}$

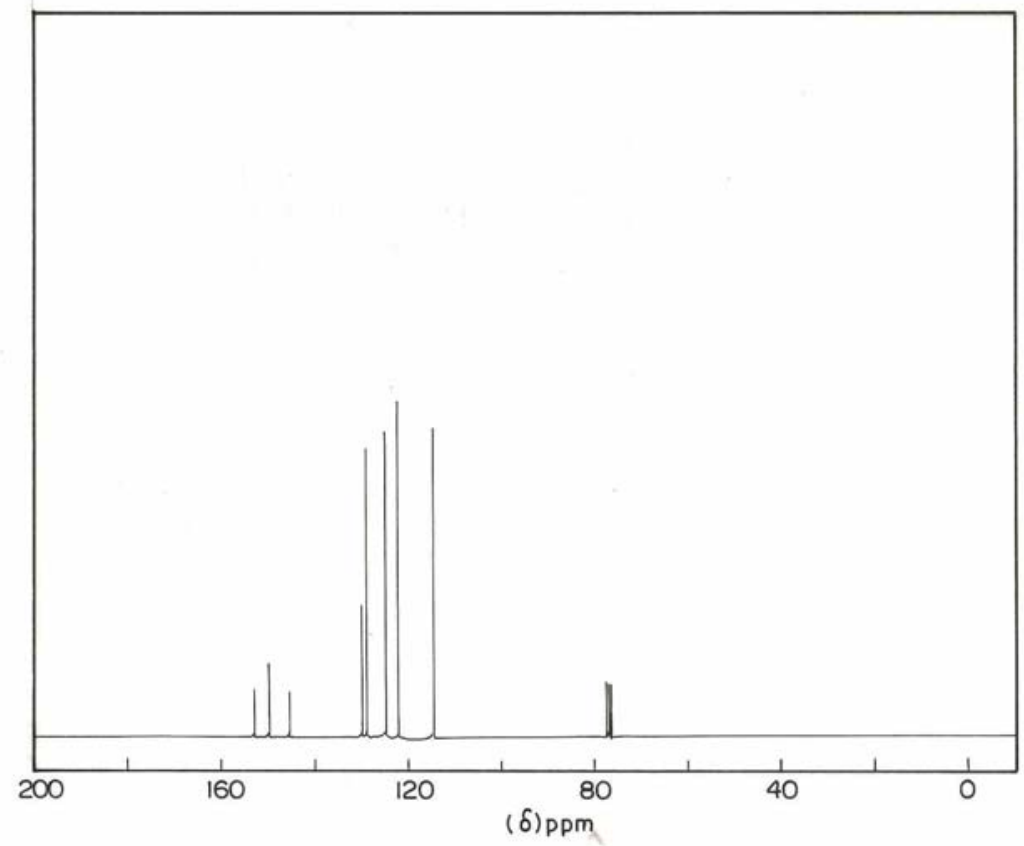

Figure $8 .{ }^{13} \mathrm{C}$ NMR spectrum of 4BAA 


\section{MASS SPECTRUM}

The structure of the compound was further confirmed by Mass spectrum (Figure 9). The mass spectrum shows a peak at $\mathrm{m} / \mathrm{z} 197$, corresponds to the molecular ion peak (ie $\mathrm{M}+$ ). Similarly the base peak appeared at $m / z 196$ corresponds the (M+ - 1). From the results of ${ }^{1} \mathrm{H}-\mathrm{NMR},{ }^{13} \mathrm{C}-\mathrm{NMR}$ and Mass spectra the structure of a prepared compound was confirmed.

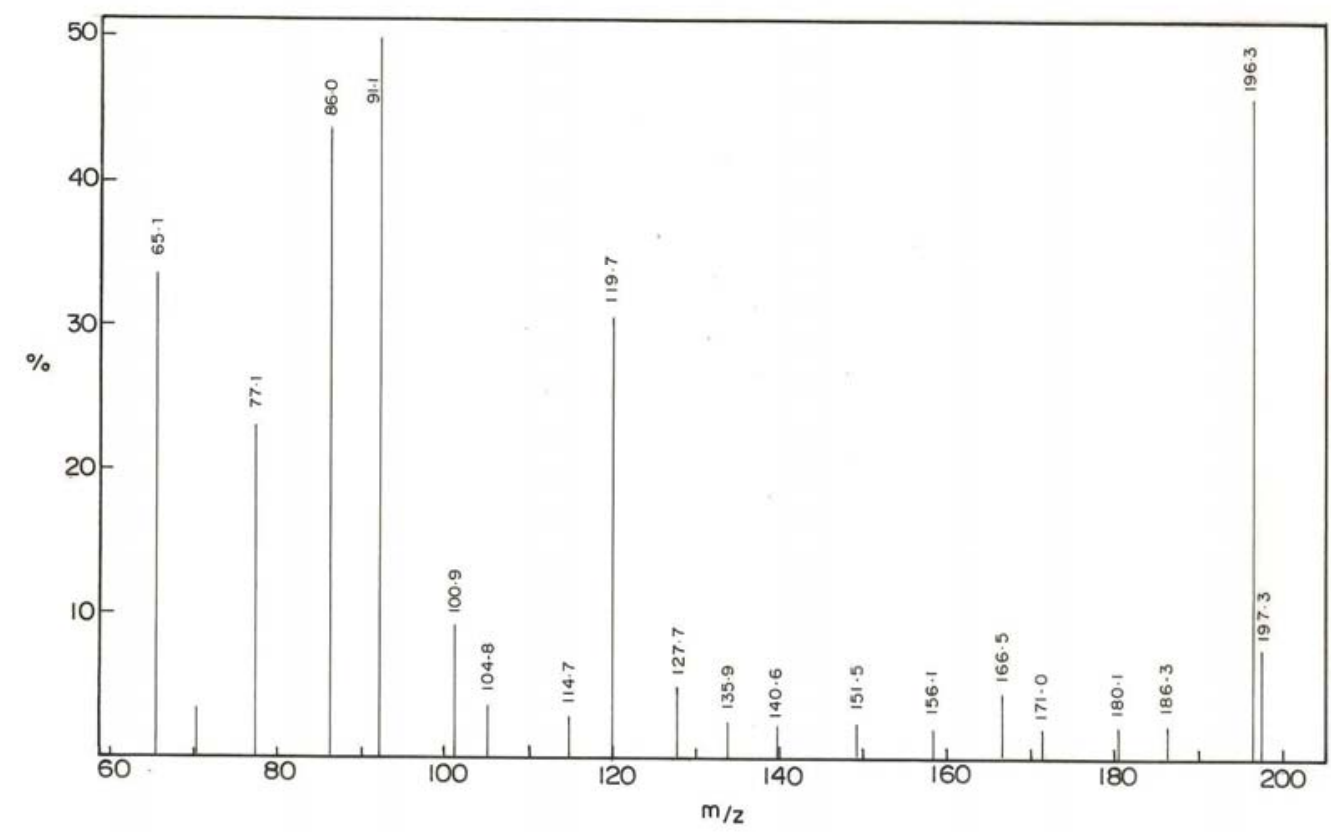

Figure 9. Mass spectrum of 4BAA

\section{THERMAL STUDIES}

The thermal behavior of the sample was assessed by TG/DTA analyses using the instrument NETZSCHSTA 409C. The TGA was carried out in nitrogen atmosphere at a heating rate of 20 $\mathrm{K} / \mathrm{min}$ in the temperature range of 10 to $1400^{\circ} \mathrm{C}$. The TG/DTA and DSC traces of 4BAA crystalline sample are shown in Figures 10 and 11 respectively. There is a sharp weight loss at around $125^{\circ} \mathrm{C}$ which is attributed to the volatilization of 4BAA. Below the onset of volatilization no loss of weight is observed and hence it is clear that there is no lattice entrapped water inside the crystal.

The DSC trace of 4BAA shows an intense sharp exotherm covering the temperature range 100 to $250^{\circ} \mathrm{C}$. This corresponds to the volatilization of the sample observed in the figure. It was also confirmed by capillary method which involved careful introduction of finely powdered 4BAA into a fine capillary and insertion of it into the melting point apparatus. The temperature was raised at a controlled rate and the meting point was determined. The value determined by this method coincides with origin of the first exotherm in the DTA trace. Based on the result of 
TG/DTA, the maximum temperature for NLO application of this crystal is limited to $190^{\circ} \mathrm{C}$. The DSC spectrum (Figure 11) shows an exothermic peak at $124^{\circ} \mathrm{C}$. The peak at $124^{\circ} \mathrm{C}$ corresponds to the melting since it $\mathrm{s}$ nearly equal to the experimental value of melting point $\left(124^{\circ} \mathrm{C}\right)$ as observed in the TGA trace.

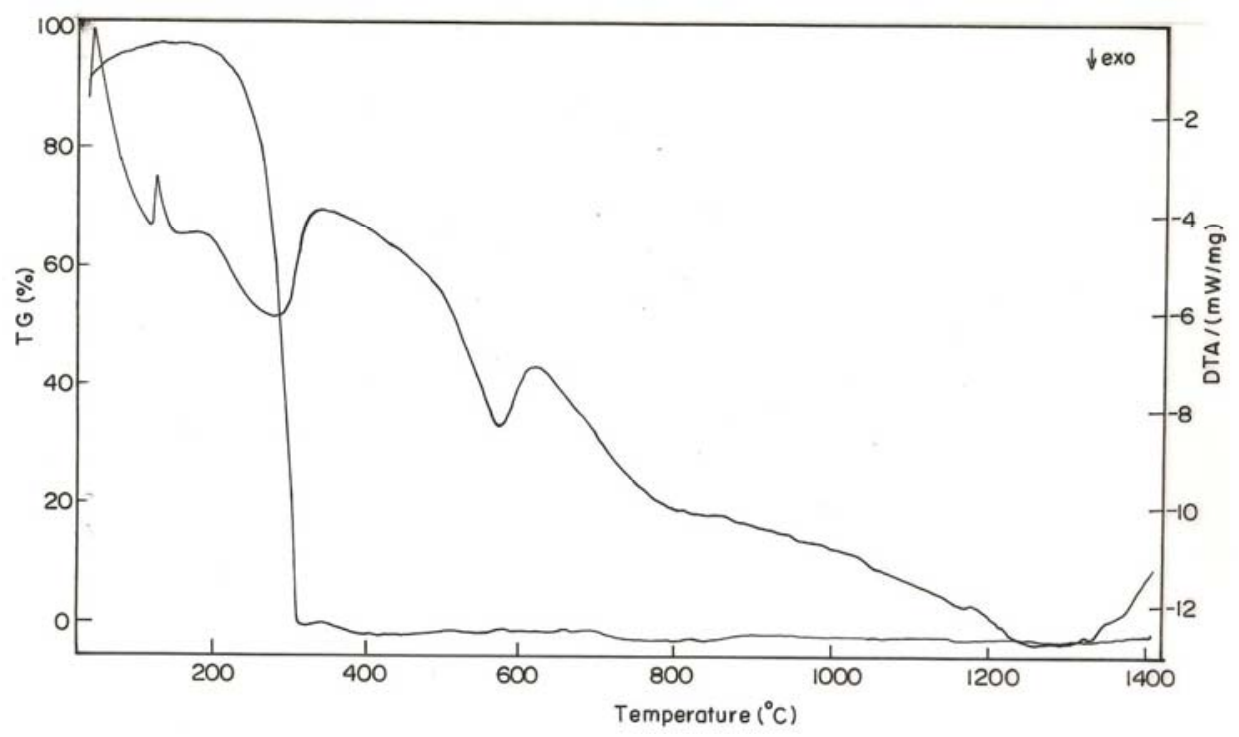

Figure 10. TG/DTA spectrum of 4BAA

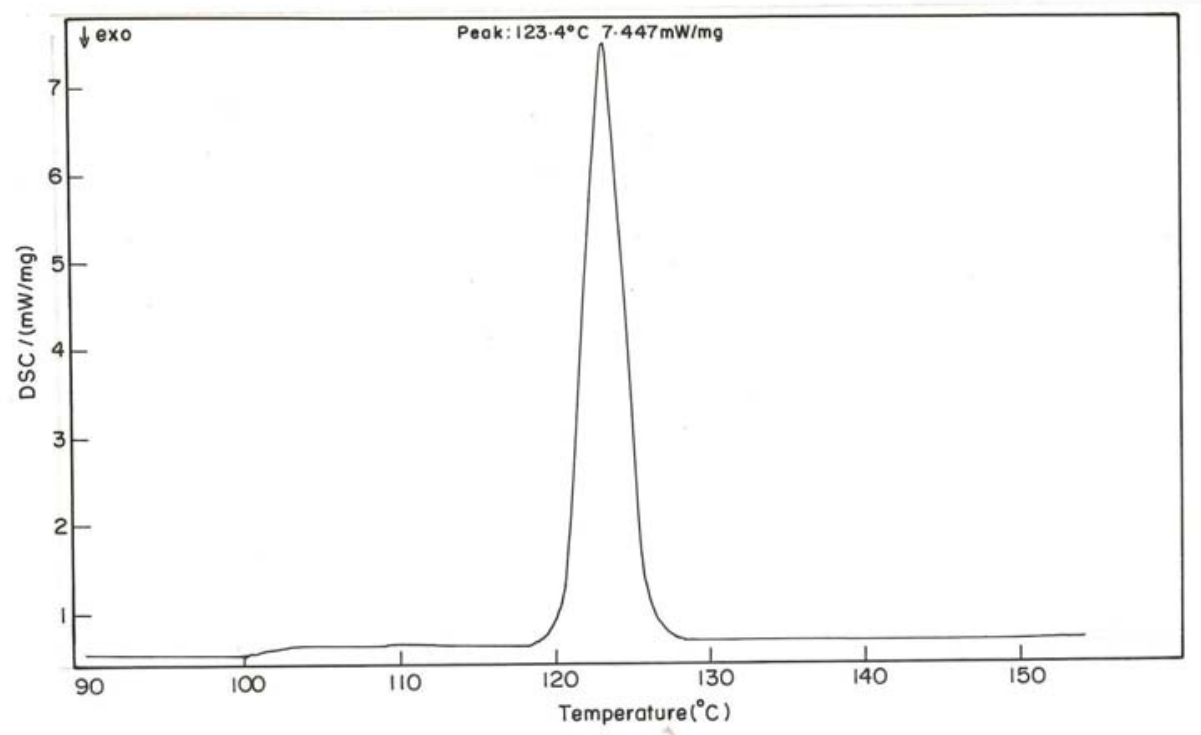

Figure 11. DSC spectrum of 4BAA 


\section{NLO STUDIES}

Powder SHG test offers the possibility of assessing the non-linearity of materials. The SHG of 4BAA crystal was confirmed by Kurtz SHG test. The crystal was illuminated by spectra physics Quanta-ray Nd:YAG laser using the first harmonic output of $1064 \mathrm{~nm}$, with a pulse width of 8 ns. The emission of green radiation from the 4BAA confirms the second harmonic generation in the crystal.

\section{CONCLUSIONS}

An organic material of 4BAA was synthesized by diazotization and diazocoupling schemes. Single crystal of 4BAA was successfully grown by slow evaporation technique at room temperature. The single crystal X-ray diffraction shows that 4BAA crystallize in the monoclinic system with space group of $P 2{ }_{1}$. FTIR, ${ }^{1} \mathrm{H} \&{ }^{13} \mathrm{C}$ NMR and mass spectral analyses confirm the formation of 4BAA and the presence of their functional groups. Optical transparency study confirms that 4BAA is transparent in entire visible region and band gap energy is $3.4 \mathrm{eV}$. Thermal studies reveal that the sample is thermally stable and has higher melting point. The NLO test confirms the SHG in 4BAA.

\section{ACKNOWLEDGMENT}

It is a pleasure to acknowledge Dr. A. John Maria Xavier, Lecturer, Department of Chemistry, Loyola College, Chennai for his constant help, support and encouragement.

\section{REFERENCE}

[1]. H. O. Marcy, L. F. Warren, M. S. Webb, C. A. Ebbers, S. P. Velsko, G. C. Kennedy, and G. C. Catella, Appl. Opt. 31 (1992) 5051.

[2]. X. Q. Wang, D. Xu, D. R. Yuan, Y. P. Tian, W. T. Yu, S. Y. Sun, Z. H. Yang, Q. Fang, M. K. Lu, Y. X. Yan, F. Q. Meng, S. Y. Guo, G. H. Zhang, and M. H. Jiang, Mat. Res. Bull. 34 (1999) 2003.

[3]. T. Pal, T. Kar, G. Bocelli, and L. Rigi, Crystal Growth \& Design, 4 (2004) 743.

[4]. S. Manivannan, and S. Dhanuskodi, J. Cryst. Growth 262 (2004) 473.

[5]. W. Nie, Adv. Mater. 5 (1993) 520.

[6]. T.J. Marks and M.A. Ratner, Angew. Chem. Int. Ed. Engl. 34 (1995) 155.

[7]. J. Park and J. Koh, Dyes and Pigments, 82 (2009) 347.

[8]. V. Krishnakumar, G. Eazhilarasi, R. Nagalakshmi, M. Piasecki, I.V. Kityk and P. Bragiel, Eur. Phys. J. Appl. Phys. 42 (2008) 263.

[9]. M. Jamkowski, A. Kudelski, J. Bukowska and K. Jackowska. J. Electroanal. Chem. 385 (1995) 177.

[10]. S. Urania Zissi, E. Michael Kornaros and C. Gerasimos Lyberatos, Water Environment Research, 71 (1999) 323. 
[11]. T. Kishore Kumar, S. Janarthanan, S.M. Ravikumar, S. Pandi, M. Vimalan, P. Sagayaraj and D. Prem Anand, J. Mater. Sci. Technol. 24 (2008) 891.

[12]. T. Kishore Kumar, S. Janarthanan, M. Victor Antony Raj, S. Pandi, P. Sagayaraj and D. Prem Anand, J. Phys. Chem. Solids, 69 (2008) 2634.

[13]. T. Kishore Kumar, S. Janarthanan, S. Pandi, S. Selvakumar and D. Prem Anand, Crystal Growth \& Design, 9 (2009) 2061.

[14]. P.M. Ushasree, R. Jayavel and P. Ramasamy, Mater. Sci. Eng. B, 65 (1999) 153.

[15]. Charles Kittel, Introduction to Solid State Physics, John Wiley and Sons, $7^{\text {th }}$ edition Singapore, 2007.

[16]. R. Bairava Ganesh, V. Kannan, R. Sathyalakshmi and P. Ramasamy, Mater. Lett. 61 (2007) 706. 
Figure captions

Figure 1. Reaction schemes of 4BAA

Figure 2. Solubility curve of $4 \mathrm{BAA}$ as a function of temperature

Figure 3. Photograph of as grown 4BAA single crystal

Figure 4. FTIR spectrum of $4 \mathrm{BAA}$

Figure 5. UV-Vis-NIR spectrum of 4BAA

Figure 6 . The structure of 4BAA

Figure 7. ${ }^{1} \mathrm{H}$ NMR spectrum of 4BAA

Figure $8 .{ }^{13} \mathrm{C}$ NMR spectrum of $4 \mathrm{BAA}$

Figure 9. Mass spectrum of 4BAA

Figure 10. TG/DTA spectrum of 4BAA

Figure 11. DSC spectrum of 4BAA 